\title{
A decisáo de Priapo, na sátiva I, 8 de Horácio: A fuga das feiticeiras como representação de uma nova era
}

\section{Arlete José Mota}

Universidade Federal do Rio de Janeiro

O antigo cemitério onde um protetor Priapo assiste a uma prática usual de feitiçaria é delimitado - cercado. Espaço reconhecido no passado, convergente, como salienta Rosendahl ${ }^{1}$ :

\begin{abstract}
Tudo é potencialmente sagrado, mas apenas em alguns lugares escolhidos o potencial é realizado. A manifestação de poder do sagrado em determinados lugares o diferencia dos demais lugares. O poder do sagrado pode ser atraente, tornando o lugar um centro convergente de crentes, ou pode se apavorante e repelente, tornando o lugar tabu, considerado maldito.
\end{abstract}

Maldito: talvez o vocábulo expresse com exatidão uma referência não só a um local, mas principalmente a um tempo anterior ao vivenciado no período da Paz Romana. Mas se a descrição da cena de magia pode parecer ao leitor algo assustador, o talento de Horácio a transforma: usa o riso, possivelmente transgredindo - se pensarmos que comportamentos (e ideias) podem ser seguidos, questionados ou transgredidos e o riso pode ser meio de reflexão, talvez mudança. $\mathrm{Ou}$, como afirma $\mathrm{Minois}^{2}$, na sátira I, 8, ”o horror torna-se cômico, e o risivel horrivel'. É possível acreditarmos na criação de um espaço dramático , onde as feiticeiras se deslocam, fugindo da "manifestação" de Priapo. É o deus dos jardins que de forma inesperada - e cômica - propóe a mudança de uso do espaço público. Seria a mudança de uma forma de pensar a prática religiosa. Náo devemos, entretanto, perder de vista o que pode

\footnotetext{
${ }^{1}$ Zeny, ROSENDAHL. Espaço e religião: uma abordagem geográfica. 2ed. Rio de Janeiro: EDUERJ, 2002, p. 68.

${ }^{2}$ Georges, MINOIS. História do riso e do escárnio. Trad. Maria Elena O. Ortiz Assumpção. São Paulo: Editora UNESP, 2003, p.95.
} 
representar o texto naquele contexto específico, como salienta Gross ${ }^{3}$ : " $A$ escrita seduz, possuindo um poder intrinseco. Mas a escrita também reduz, recorta a mensagem, revelando de forma obliqua".

Proibidos ou difundidos ao longo dos séculos, ao sabor dos ventos de ideais políticos ou filosófico-religiosos, as produçôes marcantes dos gêneros do riso passaram por processos táo distintos quanto o da aceitação e o da repulsa e a proibição. E quanto às questôes teóricas que tratam da produção do risível, as manifestaçóes do riso são estudadas sob perspectivas diferentes. Há, por exemplo, consideraçóes importantes que devem ser discutidas a respeito de noçôes físico-biológicas e a repercussão do ato de rir na saúde mental. Já no que diz respeito ao emprego literário do riso, podemos nos ater aos estudos dos gêneros e dos mecanismos de produção do riso, uma vez que o riso no texto literário pode representar um meio de expressar opinióes e, principalmente, a visão de mundo de uma determinada sociedade.

$\mathrm{Na}$ literatura latina, encontram-se poetas exímios na arte de fazer rir (e refletir). De Plauto a Marcial, por exemplo, em uma abordagem cronológica, observamos aqueles que serão os chamados mestres da comédia, da sátira e do epigrama - gêneros que encontraram terreno profícuo entre os homens marcados pelo Italum acetum, o "vinagre italiano" a que se refere Horácio (Italo perfusus aceto, Sátiras, I, 7, 32 -"cheio do vinagre italiano"). Convém pensarmos igualmente nas funçóes do risível, como destacam D'Angeli e Paduano ${ }^{4}$ : "O riso se liga à pretensão, verdadeiramente divina, de instituir o mundo como sistema significativo e equilibrado".

Mesmo reconhecendo as diferenças estruturais entre os gêneros do riso na literatura latina, não podemos deixar de citar os elementos convergentes relacionados à descrição por vezes detalhada de características físicas e comportamentais de uma quantidade expressiva de personagens. É possível associarmos os personagens das sátiras de Horácio e de Juvenal ou dos

\footnotetext{
${ }^{3}$ Eduardo, GROSS. Escrita e sacralidade. In: Eduardo, GROSS. Manifestaçóes literárias do sagrado. Juiz de Fora: Editora UFJF, 2002, p.08.

${ }^{4}$ Concetta, D`ANGELI; Guido, PADUANO. O cômico. Trad. Caetano Waldrigues Galindo. Curitiba: Editora UFPR, 2007, p.111.
} 
epigramas de Marcial aos perfis traçados por Plauto, a partir dos personagenstipo da Comédia Nova Grega.

A sátira, que, na literatura latina representava um gênero poético formalmente definido, conceitualmente bastante diferente das concepçóes modernas que definem uma modalidade literária, tem em Horácio e Juvenal seus expoentes. E sobre Horácio não faltam referências a uma perfeição formal, no conjunto de sua obra, e a elementos considerados biográficos.

Mantendo as características essenciais do gênero satírico latino, as Sátiras horacianas apresentam uma espécie de quadro vivo onde personagens (às vezes, o próprio poeta transformado em personagem) movimentam-se, dando a conhecer seus hábitos e ideias. Os temas dos chamados Sermones, "Diálogos" - vocábulo que pode designar uma possível interação com o leitor, de certa forma participante da ação - são os mais variados possíveis: desde notas sobre a eterna insatisfação humana e relatos de viagem até questôes relacionadas à visão de um crítico literário. Os tipos descritos são delineados, sem as formas caricaturais de um personagem plautino, como Euclião - afinal Horácio é o poeta da justa medida-, mas em traços nítidos e inquestionáveis, como os orgulhosos, os falsos epicuristas, as feiticeiras da sátira I, 8. Questóes comportamentais ganham destaque em quase todas as sátiras, mas em contraste com os maus exemplos de alguns de seus personagens destacam-se valores que pertencem aos novos ideais do período. São inquestionáveis as referências à política imperial e a busca por um homem ideal - caracterizado pela uirtus, pela pietas e pela fides.

A sátira I, 8, conhecida como "As feiticeiras", considerada a mais divertida do corpus, caracteriza-se em termos estruturais essencialmente pela presença de elementos narrativos como narrador, personagem e localizaçáo espaciotemporal. A ação descrita pelo narrador Priapo, confere certa noção de movimento, o que aproximaria a sátira das comédias de Plauto, em especial dos recursos cênicos utilizados nas fabullae motoriae - o movimento constante como o do seruus currens para provocar o riso do público.

O narrador da sátira é a estátua do deus Priapo, esculpida em um tronco de figueira: Olim truncus eram ficulnus, inutile lignum (v.1), "eu era 
outrora um tronco de figueira, madeira inútil'. Há aqui um falso distanciamento do poeta. Recorramos aqui à Ode IV, 3, v. 23, quando o poeta se diz Romanae fidicen lyrae, "tocador da lira romana". Horácio não poeta dos combates e das glórias militares, mas dos confrontos ideológicos e comportamentais.

Em termos estruturais, o poema pode ser dividido em três partes. $\mathrm{Na}$ primeira (vv. 1- 16), observamos as origens do narrador e as questóes relacionadas à delimitação territorial, além de referências aos valores temporais; na segunda, vv. 17-45, vemos a cena de magia e o horror de Priapo; e, na terceira parte, vv. 46-50, temos a solução - diríamos engenhosa - da estátua. Vamos nos ater a algumas passagens.

O tempo da narrativa é o presente. Os verbos eram (v.1), “era”, e uidi (v.23), "vi", entretanto, mostram um distanciamento temporal necessário. O passado é representado pela utilização do local como cemitério, que serviria a práticas não condizentes com os novos ideiais do período augustano e o presente se caracteriza pela construção dos novos jardins. $\mathrm{O}$ afastamento temporal, no jogo entre passado e presente criado pelo poeta, representa valioso recurso literário. Como salienta Reñones ${ }^{5}$ :

É algo simples e óbvio, mas que esquecemos frequentemente. A resolução de um problema muitas vezes necessita de um distanciamento suficiente, seja afetivo, espacial ou temporal, para que possamos ver o problema por outros ângulos, com outras ligaçôes, num contexto maior (...). Esta por sinal umas das estratégias mais comuns nas comédias, usar dos momentos de tensão explosiva para resolver problemas - sempre infrutiferamente tratados...

Quando do afastamento, além de uma visáo mais ampla, que considera os afetos e a razão - os participantes, o eu e o nós - conseguimos trabalhar melhor sobre o que está emergindo. Ao olhar para o tema estaremos com uma visão mais ampla, seja pelo distanciamento e relaxamento, seja pela "consequência" deles, a criatividade.

O advérbio nunc (v. 1), "agora", transporta o leitor ao presente da narrativa e situa as atividades das feiticeiras em um jardim. Novos tempos,

5 Albor Vives, REÑONES. O riso doído. Atualizando o mito, o rito e o teatro grego. São Paulo: Ágora, 2002, p.174. 
novos espaços. Ou melhor: revitalização, reutilização do espaço, conforme Eliade $^{6}$, "qualquer nova instalação humana é, em certo sentido, uma reconstrução do mundo". Metaforicamente, pode-se relacionar a renovação do antigo cemitério à revitalização de crenças e valores morais dos antepassados pretendida por Augusto.

Cabe aqui mencionar outra característica formal da sátira oitava, a presença de personagens, o que também a aproxima do gênero narrativo elementos narrativos estáo presentes em especial nas sátiras 5, 7, 8 e 9 do primeiro livro da Sátiras. Não nos referimos apenas a Canídia e Ságana, cuja ação é descrita pelo deus, mas a Pantolabo, Nomentano, Júlio, Pediacia e Vorano - embora sejam apenas citados pelo poeta, também são marcados por costumes inapropriados aos novos tempos. Ressaltamos que o narrador prefere render-se aos seus hábitos a aceitar as atividades das feiticeiras. Acrescentamos ainda que a escolha do deus narrador fundamenta-se não só na sua atuação como protetor dos pomares e jardins, mas também como um importante recurso no que diz respeito à criação do risível - a figura medrosa do deus e o recurso sonoro utilizado para afugentar as feiticeiras (o som semelhante a um flato) estão associada a um ideal político que fica claro no texto. E mesmo que questionemos a utilização da obra como instrumento de veiculação de uma proposta política é inquestionável o talento de Horácio ao associar forma perfeita, elementos do cômico e profunda reflexáo a respeito de comportamentos em sociedade. Como afirma $\mathrm{Grimal}^{7}$, ao se referir ao chamado Século de Augusto, na periodização da literatura latina,

A poesia por fim é a linguagem dos deuses; possui uma natureza sobrehumana; a sua beleza, o seu ritmo, o seu encantamento fazem dela como que uma revelação de verdades que, de outro modo, nos seriam inacessíveis. Era natural que o século de Augusto, que viveu a transformação da religião nacional, fosse o grande século por excelência da poesia inspirada.

\footnotetext{
${ }^{6}$ Mircea, ELIADE. Tratado de história das religióes. Trad. Fernando Tomaz e Natália Nunes. São Paulo: Martins Fontes, 2008, p.301.

7 Pierre, GRIMAL. O século de Augusto. Trad. Rui Miguel Oliveira Duarte. Lisboa: Ediçóes 70, 1992, p.79.
} 
Quanto à Canídia e Ságana, lembramos ainda que são citadas por Horácio em outro poema, no Epodo $\mathrm{V}$, e podem representar uma alusão a feiticeiras conhecidas da época. E sobre as práticas descritas na sátira transcrevemos o comentário de Montero $^{8}$, quando apresenta as relaçóes entre a adivinhação não oficial e as práticas mágicas, atividades marginalizadas, acrescentando:

Uma atividade nada desprezível de magas e feiticeiras consistiu, portanto em dar a conhecer a uma clientela essencialmente feminina acontecimentos tanto do passado como do futuro, geralmente colocando-se em contato com o mundo dos mortos mediante procedimentos necromânticos.

A cena de magia é descrita por Horácio, com riqueza de detalhes, nos versos 17 a 44. Priapo é testemunha da cena. Impotente, envergonha-se por não poder de alguma forma impedi-las:

\footnotetext{
cum mihi non tantum furesque feraeque suetae hunc uexare locum curae sunt atque labori quantum carminibus quae uersant atque uenenis humanos animos; has nullo perdere possum nec prohibere modo, simul ac uaga luna decorum protulit os, quin ossa legant herbasque nocentis.

Vidi egomet nigra succinctam uadere palla Canidiam pedibus nudis passoque capillo, cum Sagana maiore ululantem; pallor utrasque fecerat horrendas aspectu. Scalpere terram unguibus et pullam diuellere mordicus agnam coeperunt; cruor in fossam confusus, ut inde manis elicerent animas responsa daturas. Lanea et effigies erat, altera cerea; maior lanea, quae poenis compesceret inferiorem; cerea suppliciter stabat, seruilibus ut quae iam peritura modis... (vv. 17-32)
}

\footnotetext{
${ }^{8}$ Santiago, MONTERO. Deusas e adivinhas. Mulher e adivinhação na Roma antiga. Trad. Nelson Canabarro. São Paulo: Musa, 1998, pp.44-45.
} 
(Neste momento, os ladróes e as feras habituadas a afligir o local não representam para mim uma preocupação e um trabalho tão grandes quanto as mulheres que, com seus encantamentos, perturbam os espíritos humanos. De forma alguma posso destruí-las ou proibi-las de, logo que a lua errante mostra sua bela face, recolher os ossos e as ervas maléficas. Eu mesmo vi Canídia, com um vestido negro, pés nus e cabelos desgrenhados, caminhar uivando com Ságana, a mais velha: a palidez fizera-as uma e outra horrendas no aspecto. Começaram a cavar a terra com as unhas e a dilacerar a dentadas uma ovelha negra; sangue fora derramado na cova para que pudessem evocar os manes, as almas que trariam as respostas. Havia uma imagem de lá e outra de cera; a maior era a de lá, que subjugaria com castigos a menor. a de cera mantinha-se em posição suplicante como os escravos prestes a morrer.)

As feiticeiras invocam Hécate e Tisífone. Até a lua parece se esconder, diante das atividades de Canídia e Ságana:

\author{
Hecaten uocat altera, saeuam \\ altera Tisiphonen; serpentis atque uideres \\ infernas errare canes lunamque rubentem, \\ ne foret his testis, post magna latere sepulcra. \\ Mentior at siquid, merdis caput inquiner albis \\ coruorum atque in me ueniat mictum atque cacatum \\ Iulius et fragilis pediatia furque Voranus. (vv. 33-39)
}

(Uma invoca Hécate, a outra, a cruel Tisífone. Ver-se-iam errar serpentes e cadelas infernais; poder-se-ia ver a lua avermelhada esconder-se atrás dos grandes sepulcros para não ser testemunha destes fatos. Se eu digo alguma mentira, que minha cabeça fique suja com os brancos excrementos dos corvos e que venham urinar e defecar em mim Júlio, o frágil Pediacia e o ladrão Vorano.)

\title{
A atividade das feiticeiras aponta para um ritual, reconhecido de alguma forma pelos contemporâneos do poeta. Segundo Peirano?',
}

${ }^{9}$ Mariza, PEIRANO. Rituais ontem e hoje. Rio de Janeiro: Zahar, 2003, p.10. 
...partindo do princípio de que uma sociedade possui um repertório relativamente definido (embora flexível), compartilhado e público de categorias, classificaçóes, formas, valores etc., o que se encontra no ritual também está presente no dia-a-dia - e vice-versa. Consideramos o ritual um fenômeno especial da sociedade, que nos aponta e revela representaçôes e valores de uma sociedade, mas o ritual expande, ilumina e ressalta o que já é comum a um determinado grupo (...) Rituais são bons para transmitir valores e conhecimentos e também próprios para resolver conflitos e reproduzir as relaçôes sociais.

Voltemos à localização espacial, elemento do texto narrativo utilizado pelo poeta. Pensamos no texto literário formalmente delimitado pelo gênero satírico, onde a "mistura" (satura) é a característica fundamental, pensamos em um território marcado, pensamos principalmente em um espaço dramático, onde os elementos do risível propiciam uma espécie de transgressão.

Além das marcas temporais já citadas por nós, a localização do espaço em que ocorre a cena de magia é também determinante. Notamos uma preocupaçáo em delimitar o espaço geográfico em que acontecem os fatos. $\mathrm{O}$ leitor pode reconhecer o local e vivenciá-lo, na imaginação: pode percorrer caminhos. E é exatamente esse movimento que se constitui num dos elementos essenciais para a compreensão dos possíveis objetivos do poeta.

Há um espaço real: Mille pedes in fronte, trecentos cippus in agrum /hic dabat, heredes monumentum ne sequeretur ${ }^{10}$. (vv. 12-13). Os limites são traçados e existem elementos na sátira que possibilitam imaginar a existência de uma estátua de Priapo nos novos jardins de Mecenas, conhecidos pelos demais poetas de seu círculo literário.

Há um espaço dramático. Segundo Pavis ${ }^{11}$ : "Espaço dramático é o espaço dramatúrgico do qual o texto fala, espaço abstrato e que o leitor ou espectador deve construir pela imaginação (ficcionalizando)". Cabe ao leitor

\footnotetext{
${ }^{10}$ Interpretação: "Aqui um marco delimitava mil pés para a frente e trezentos pés de comprimento, a fim de que o local não fosse cedido a herdeiros."

${ }^{11}$ Patrice, PAVIS. Dicionário de teatro. Trad. J. Guinsburg e Maria Lúcia Pereira. São Paulo: Perspectiva, 2007, p.132.
} 
moderno imaginá-lo, como coube ao leitor contemporâneo de Horácio conhecedor do espaço - vivificar o que naturalmente faz parte de sua cultura. Em cena atuam as feiticeiras, com suas características físicas notáveis, como a palidez, e com seus objetos rituais. Em cena atua também Priapo, que tem como missão proteger o local - na verdade é um espantalho. A decisão do deus dos jardins imprime ao texto uma necessária mudança de tom, criado inicialmente pela atmosfera lúgubre.

O texto de Horácio propóe um observador (espectador) da ação, o leitor. Simplificando o conceito, recorremos a Bentley"12: "a situação teatral, reduzida a um minimo, é que A personifica $B$ enquanto $C$ olha". Observar a ação das feiticeiras, como espectador torna o leitor cúmplice do deus, que é um Priapo assustado e sem um poder real de atuar contra elas. $\mathrm{O}$ recurso imagético corporifica os personagens, tornando-os verdadeiros. Ou verossímeis.

À guisa de conclusão, poderíamos dizer que a inadaptação inicial do assustado Priapo, diante das feiticeiras - na verdade um deus transformado em "espantalho" - dá lugar a uma decisão nada convencional: um barulho, provocado por uma rachadura na madeira, semelhante a um flato. Desejaria o leitor desavisado uma série de fenômenos que transformariam o local e eliminariam Canídia e Ságana. Mas não é essa a decisão de Horácio. Não é essa a fórmula dos gêneros do riso - se é que existe uma fórmula. Fazer o leitor assistir à cena horripilante, mesmo que na imaginação, alterando por completo seu estado anímico, do horror à gargalhada: eis a decisão do poeta. Eis a sua forma de falar de uma época, de um ritual. Talvez o poeta fosse simples mensageiro, talvez um dos atores da comédia.

\footnotetext{
${ }^{12}$ BENTLEY, Eric. A experiência viva do teatro. Trad. Álvaro Cabral. Rio de Janeiro: Zahar, 1981, p.142.
} 